\title{
Improvements in nanoscale zero-valent iron production by milling through the addition of alumina
}

D. Ribas 1,2

M. Cernik 3

V. Martí 1,2

J. A. Benito $1,4,5, *$

Phone +34-934010946

Email josep.a.benito@upc.edu

1 Fundació CTM Centre Tecnològic de Manresa, Plaça de la Ciència 2, 08243 Manresa, Spain

2 Department of Chemical Engineering, ETSEIB, Universitat Politècnica de Catalunya, Av. Diagonal 647, 08028 Barcelona, Spain

3 Institute for Nanomaterials, Advanced Technologies and Innovation, Technical University of Liberec, Studentská 1402/2, 46117 Liberec 1, Czech Republic

4 Department of Materials Science and Metallurgical Engineering, EUETIB, Universitat Politècnica de Catalunya, Comte d'Urgell 187, 08036 Barcelona, Spain

5 Materials Science Department, Pavelló E. ETSEIB, Av. Diagonal, 647, 08028 Barcelona, Spain

\section{Abstract}

A new milling procedure for a cost-effective production of nanoscale zero-valent iron for environmental remediation is presented. Conventional ball milling of iron in an organic solvent as Mono Ethylene Glycol produces flattened iron particles that are unlikely to break even after very long milling 
times. With the aim of breaking down these iron flakes, in this new procedure, further milling is carried out by adding an amount of fine alumina powder to the previously milled solution. As the amount of added alumina increases from 9 to $54 \mathrm{~g} \mathrm{l}^{-1}$, a progressive decrease of the presence of flakes is observed. In the latter case, the appearance of the particles formed by fragments of former flakes is rather homogeneous, with most of the final nanoparticles having an equivalent diameter well below $1 \mu \mathrm{m}$ and with an average particle size in solution of around $400 \mathrm{~nm}$. An additional increase of alumina content results in a highly viscous solution showing worse particle size distribution. Milled particles, in the case of alumina concentrations of $54 \mathrm{~g} \mathrm{l}^{-1}$, have a fairly large specific surface area and high Fe-(0) content. These new particles show a very good $\mathrm{Cr}(\mathrm{VI})$ removal efficiency compared with other commercial products available. This good reactivity is related to the absence of an oxide layer, the large amount of superficial irregularities generated by the repetitive fracture process during milling and the presence of a fine nanostructure within the iron nanoparticles.

\section{Keywords}

nZVI

Nanostructured iron

Milling

Environmental remediation

Commercial product

\section{Introduction}

The use of iron nanoparticles, more commonly known as nano zero-valent iron (nZVI), for groundwater remediation has been investigated for the last 10-15 years because of its great potential to reduce subsurface contaminants such as halogenated organic compounds (Wang and Zhang 1997), transition metals, including chromium (Klimkova et al. 2011) and a wide range of other chemical pollutants (Crane and Scott 2012). Even though there are more than 50 pilot or full-scale applications of nZVI for in situ applications worldwide (Yan et al. 2013; Mueller et al. 2012), there are certain critical points that require improvement so as to make possible large-scale commercialization of this technology. 
One of the problems is nZVI's low mobility in porous media given that iron nanoparticles (20-150 $\mathrm{nm}$ in diameter) have a strong tendency to aggregate forming a network of micrometre-sized particles (O'Carroll et al. 2013; Phenrat et al. 2007). On the other hand, there are several uncertainties concerning the use of nanotechnology as regards environmental toxicity, meaning that its use is limited by a number of countries through strict regulations (Yan et al. 2013). Finally, current production methods produce only limited quantities of nZVI at a relatively high cost, which may be the main reason why its use is not more widespread (Crane and Scott 2012; Mueller et al. 2012).

There are many methods for producing iron nanoparticles, but only a few of them are commercially available (Yan et al. 2013; Crane and Scott 2012). The use of nZVI obtained from borohydride reduction of dissolved Fe(III) in an aqueous solution (Wang and Zhang 1997) is common in controlled laboratory studies. At a commercial scale, nZVI is currently produced by gas-phase reduction of iron oxides at elevated temperatures (Uegami et al. 2006; NanoIron 2016). Finally, nZVI can also be produced by wet milling of conventional iron powder. In the latter case, stable dispersions of iron nanoparticles in an aqueous solution with an average size of $100 \mathrm{~nm}$ and good oxidation-reduction potential (ORP) have been reported (Zhang 2006). However, the use of an aqueous solution may lead to a large decrease of $\mathrm{Fe}(0)$ content due to the known reactivity of iron with water (Crane and Scott 2012).

Recently, a new milling method using non-aqueous media (Mono Ethylene Glycol) has been reported (Köber et al. 2014) and commercialized. The obtained suspensions showed a negligible loss of $\mathrm{Fe}(0)$ and a high specific surface area $\left(18 \mathrm{~m}^{2} \mathrm{~g}^{-1}\right)$. Nevertheless, milled particles had a flaky morphology of several microns in length with a thickness of less than $100 \mathrm{~nm}$. These flakes remained unbroken during milling, probably due to the high ductility of iron and the viscosity of Mono Ethylene Glycol. However, these particles showed some reactivity advantages with a lower cost than other nZVI products available on the market.

This work is focused on exploring a new milling procedure capable of breaking down the iron flakes produced by milling in organic solvents. With this aim, the study observed the effect of adding alumina during the milling process to produce nZVI. Alumina $\left(\mathrm{Al}_{2} \mathrm{O}_{3}\right)$ is a chemically inert and biocompatible material 
used in medical devices, which is very abundant in nature (Patnaik 2003; Smallman and Bishop 1999). At the same time, alumina has high mechanical strength and hardness and therefore, has the capacity to deform commercial iron powder. In this sense, the use of alumina balls during the milling of iron powder enabled to form thin iron films all around the smooth surface of alumina balls (Hao et al. 2012). It is thought that the use of irregular alumina during the milling in non-aqueous media of iron can help to break the previously described very thin flakes and then to reduce the size of the milled iron particles. Finally, it is important to note that the chemical reaction of alumina with iron can be neglected because it has only been described in dry high-energy mechanical milling processes (Paesano et al. 2004).

Since the main use of these particles is to remove contaminants from groundwater, the new milled particles' reactivity has been investigated through their capacity to reduce Cr(VI) (O'Carroll et al. 2013; Crane and Scott 2012). Hexavalent chromium Cr(VI) is a heavy metal used in many industrial applications, e.g. chromium production and leather tanning. Its reduction to trivalent chromium $\mathrm{Cr}$ (III) is a common mitigation approach in contaminated waters since a mobile and very toxic chromium species is converted to a less mobile and less toxic form (Bagchi et al. 2002). nZVI is widely studied as a remediation method for Cr(VI) (Tang and Lo 2013; Gheju 2011). Although it has been extensively studied, there is a great diversity of proposed pathways to describe chromium reduction and precipitation (Mystrioti et al. 2014).

Equation 1 describes the reaction between nZVI and Cr(VI) (Melitas et al. 2001).

$$
\mathrm{Fe}_{(\mathrm{s})}^{0}+\mathrm{CrO}_{4(\mathrm{aq})}^{2-}+4 \mathrm{H}_{2} \mathrm{O}_{(\mathrm{l})} \rightarrow \mathrm{Fe}(\mathrm{OH})_{3(\mathrm{~s})}+\mathrm{Cr}(\mathrm{OH})_{3(\mathrm{~s})}+2 \mathrm{OH}^{-} \quad 1
$$

\section{Materials and methods}

The initial iron powder was Carbonyl Iron Powder (BASF CIP-SM), with an iron content of $>99 \%$, a $d_{50}=1.57 \mu \mathrm{m}$ and a superficial surface area (SSA) of $0.7 \pm 0.1 \mathrm{~m}^{2} \mathrm{~g}^{-1}$. The milling tests were carried out in a planetary ball mill (P-5, Fritsch) using AISI 1045 steel vials with a capacity of $250 \mathrm{ml}$. In all cases, the vials were filled with $100 \mathrm{ml}$ of Mono Ethylene Glycol (MEG, Scharlab S.L.), $3 \mathrm{~g}$ of iron powder and $250 \mathrm{~g}$ of medium-carbon steel balls with a diameter of 
$\approx 2 \mathrm{~mm}$ (ref S660, PometonEspaña). The vials were purged with argon gas until a protective atmosphere was created inside them. The rotating speed was $400 \mathrm{rpm}$ and the milling cycle consisted of $30 \mathrm{~min}$ of attrition followed by $30 \mathrm{~min}$ of stand-by periods to minimize the temperature rise.

In a first set of tests, the iron was milled for different periods of time: 24, 48, 72 and $96 \mathrm{~h}$. Then, a second set of experiments was carried out. These new tests were divided into two steps. In the first step, the iron was milled for $24 \mathrm{~h}$ following the standard procedure described above. Once the vials have cooled, they were opened in a glove box in an $\mathrm{N}_{2}$ protective atmosphere, and varying amounts of irregular $\mathrm{Al}_{2} \mathrm{O}_{3}$ powder $\left(9,18,27,54\right.$ and $\left.108 \mathrm{~g} \mathrm{l}^{-1}\right)$ with an average diameter of $5 \mu \mathrm{m}$ were added to them (Presi S.A.). The vials were once again purged with argon gas and placed in the planetary ball mill for a second milling step. In this second step, milling lasted $24 \mathrm{~h}$ and followed the standard procedure described above.

After the milling process, all the slurries were sieved to remove the steel grinding balls. Milled Fe (0) particles were separated from the alumina powder using a magnetic field so as to carry out a particle characterization. The slurry was placed over a powerful permanent magnet ( $720 \mathrm{~g}$ of NdFeB, Grade N42) in order to concentrate iron particles in the bottom, supernatant was poured over it and $\mathrm{Fe}$ (0) particles were dispersed in absolute ethanol. This procedure was repeated five times.

The particle size distribution was determined in an absolute ethanol solution by Laser Diffraction Particle Size Analysis (LDPSA) (LS 13320, Beckman Coulter). All the results obtained by this method were obtained using the number of particles mode. The specific surface area (SSA) was analysed by BET gas adsorption drying the ethanol suspension with a maximum degassing temperature of $100{ }^{\circ} \mathrm{C}$ (ASAP 2020, Micromeritics). The Fe (0) content was determined in triplicate by the hydrogen production method (Liu et al. 2005a) where iron reacts with sulphuric acid added to the slurry and the volume of produced hydrogen was measured. The morphology of the milled particles was studied by Scanning Electron Microscopy (SEM) (Gemini, Zeiss). A drop of the ethanol suspension was placed on a copper support and then dried in a protective atmosphere inside a glove box. A very small presence of $\mathrm{Al}_{2} \mathrm{O}_{3}$ was confirmed by secondary electron images and energy-dispersive X-ray spectroscopy (EDS). For 
transmission electron microscopy (TEM) (Philips CM30) observation, a droplet of the ethanol suspension was placed on a 300 copper mesh grid with a supporting film made of holey carbon and then transferred to a microscope over a liquid nitrogen flask to reduce oxygen contact.

Reduction of $\mathrm{Cr}$ (VI) to $\mathrm{Cr}$ (III) was used to quantify the reactivity of the selected iron nanoparticles in batch mode. Batches were set in $250 \mathrm{ml}$ hermetic borosilicate glass bottles with an initial $\mathrm{Cr}(\mathrm{VI})$ concentration of $50 \mathrm{mg}^{-1}$ prepared from dried potassium chromate $\left(\mathrm{K}_{2} \mathrm{CrO}_{4}\right.$, p.A., AppliChem $\left.\mathrm{GmbH}\right)$. In order to simulate ions interferences and ionic strength in real water, tap water was used in all the experiments after leaving it overnight to eliminate the chlorine. By way of comparison, apart from the milled nZVI obtained in the present work, two nZVI commercial products were also tested:

(I) Commercial NANOFER 25P (NANOIRON s.r.o, Czech Republic), named "N25P". The particles are obtained by gas reduction at high temperature, being extremely reactive and pyrophoric with an SSA of $25 \mathrm{~m}^{2} \mathrm{~g}^{-1}$ and an average particle size of $50 \mathrm{~nm}$, forming aggregates of a few microns in water (Soukupova et al. 2015). The particles' Fe (0) content is $87 \% \pm 1$. For the experiments, $20 \% \mathrm{w} / \mathrm{w}$ iron water slurry was prepared and immediately used.

(II) Novel nZVI milled flakes supplied by (UVR-FIA GmbH, Germany), named "A01". The particles are produced by wet milling in MEG and they are supplied in this MEG slurry. A01 is composed mainly of iron flakes with a lateral size of several micrometres and a thickness of $<200 \mathrm{~nm}$ forming agglomerates of different sizes ranging from $200 \mathrm{~nm}$ to $45 \mu \mathrm{m}$ (Köber et al. 20152014 ). The SSA is $18 \mathrm{~m}^{2} \mathrm{~g}^{-1}$ and $\mathrm{Fe}(0)$ content is $74 \% \pm 1$.

Seven reaction batches were prepared for each type of nZVI, spiking each sample to a final iron concentration of $0.1,0.25,0.5,1.0,2.0,2.5$ and $4.0 \mathrm{~g} \mathrm{l}^{-1}$. The different types of nZVI were used as received or produced in the reactivity tests, and the $\mathrm{Al}_{2} \mathrm{O}_{3}$ and MEG were not separated from the slurries, emulating a commercial application. So as to observe the effect of alumina and MEG, a blank with the used amount of both products was prepared. Finally, it must be noted that the solutions were not buffered in order to mimic field conditions.

After nZVI addition, the solutions were put into a rotating shaker with a 
bottom-up rotation step every $60 \mathrm{~s}$ to keep nanoparticles in suspension avoiding particle settling. The batch reactors were not stirred to prevent an increase of reactivity of nanoparticles with water. Batches were allowed to react for $24 \mathrm{~h}$ after being analysed. The reference batches were analysed repeatedly over 2 months with no significant changes in $\mathrm{Cr}(\mathrm{VI})$ concentration. $\mathrm{Cr}(\mathrm{VI})$ concentration was determined colorimetrically (DR3900 Spectrometer, Hach Lange $\mathrm{GmbH}$ ) by diphenylcarbazide reaction in acid solution (US EPA method 7196A).

\section{Results}

\section{Milling without alumina}

The first tests were carried out with only medium-carbon steel balls as a grinding media. The iron was milled for different times of $24,48,72$ and $96 \mathrm{~h}$ with the aim of studying the evolution of iron powder over long milling times. The changes in morphology of the iron particles at different milling times can be observed in the SEM images in Fig. 1. After $24 \mathrm{~h}$ of milling, the initial spherical iron particles evolved to a flaky morphology with a high reduction of thickness. At the same time, the SSA also increased significantly to $8.9 \pm 0.1 \mathrm{~m}^{2} \mathrm{~g}^{-1}$. With longer milling times, no changes were observed in the aspect of the milled particles. Figure $1 \mathrm{e}$ shows a detailed view of some flakes in which thickness is less than $100 \mathrm{~nm}$.

\section{Fig. 1}

SEM images of particles milled without alumina. a Initial iron powder, $\mathbf{b}$ after $24 \mathrm{~h}, \mathbf{c}$ after $48 \mathrm{~h}, \mathbf{d}$ after $96 \mathrm{~h}$ and e detailed image of one flake of an iron particle milled for $48 \mathrm{~h}$ 


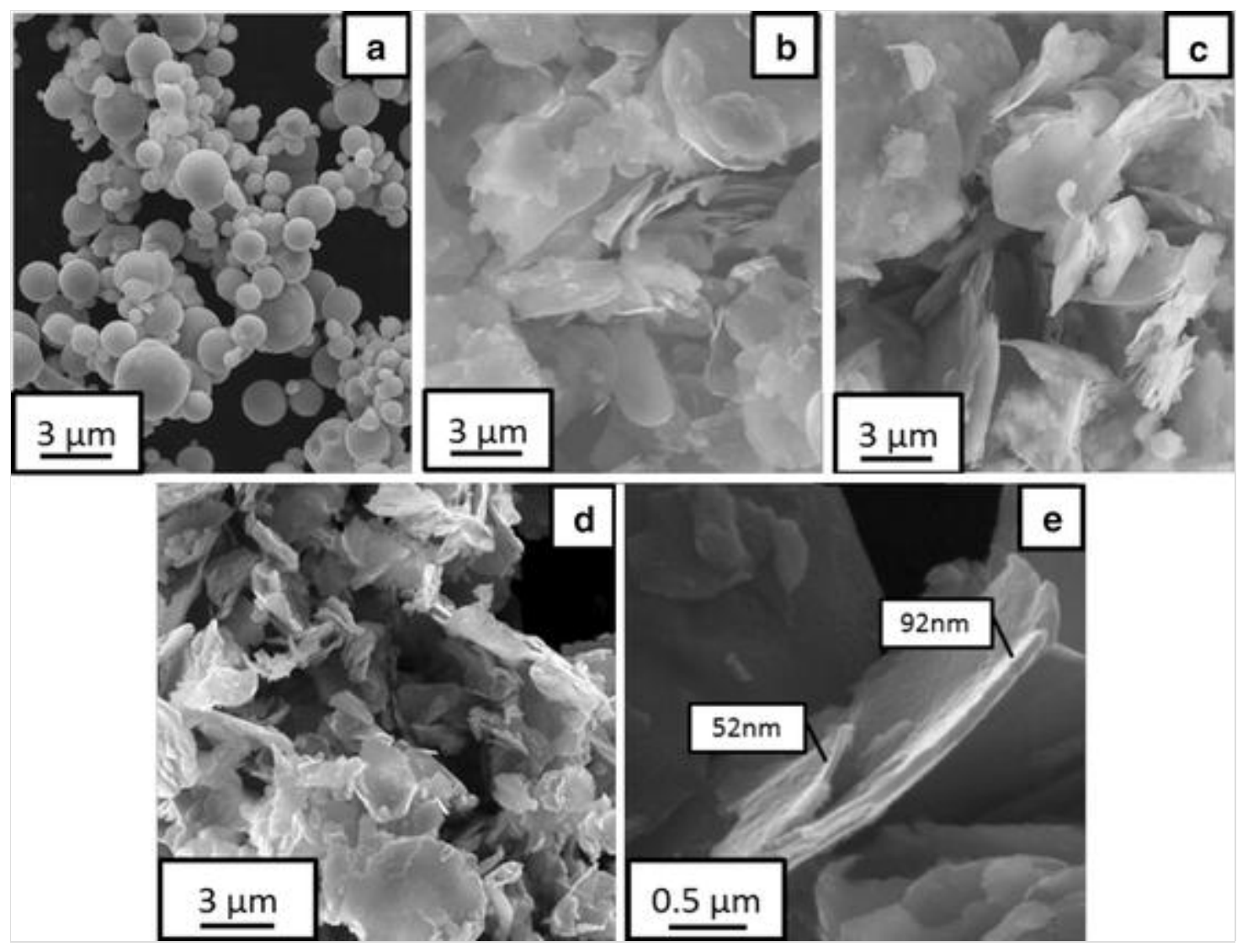

This evolution of iron powder with milling in MEG is fully in line with previous studies (Köber et al. 2014) but it is completely different from the cases in which an aqueous solution was used ( $\mathrm{Li}$ et al. 2009; Zhang 2006). In the latter case, the iron particles break rapidly and extensively leading to a high particle size reduction with a final individual particle size less than $200 \mathrm{~nm}$ and irregular morphology. This may be related to an iron embrittlement or oxidation due to the known reactivity of iron with water, which results in a sharp decrease in $\mathrm{Fe}(0)$ content (Crane and Scott 2012). On the contrary, during the milling process with MEG no reaction was observed since the $\mathrm{Fe}(0)$ content after milling was above $90 \%$ in all cases. In the absence of embrittlement, iron behaves like a soft and ductile metal and it flattens plastically under the effect of the grinding media forming the observed flakes.

Figure 2 shows the evolution with the milling time of the mean equivalent diameter of the particles $(D)$ and the percentage of particles that are below $1 \mu \mathrm{m}$ $\left(P_{\mathrm{B}}\right)$ as determined by LDPSA. The change to a flaky morphology after milling for $24 \mathrm{~h}$ led to an increase in $D$ and a reduction of $P_{\mathrm{B}}$. As the milling time increases to $48 \mathrm{~h}$, a slight reduction of the mean particle size $D$, together with a moderate increase of $P_{\mathrm{B}}$ up to $13 \%$ was observed. These changes were not 
detected in the SEM images of the dry particles in Fig. 1, and they could be related to a partial breakage of the thinner flakes that would create a certain number of smaller isolated particles in solution. However, with longer milling times, even after $96 \mathrm{~h}$, no significant changes were observed either in $D$ or in $P_{\mathrm{B}}$. In the light of these results, it seems that the current process is not able to break the flakes even at long milling times and consequently, there is not a more effective particle size reduction. The final flaky product has a very slight thickness less than $100 \mathrm{~nm}$, an interesting SSA, good reactivity against some pollutants and even good mobility (Köber et al. 2014), although agglomeration and settling of this type of milled particles has been considered to be a major problem for mobility (Velimirovic et al. 2015).

\section{Fig. 2}

Evolution of mean particle diameter $D$ and percentage of particles below $1 \mu \mathrm{m} P_{\mathrm{B}}$ over milling time, without alumina

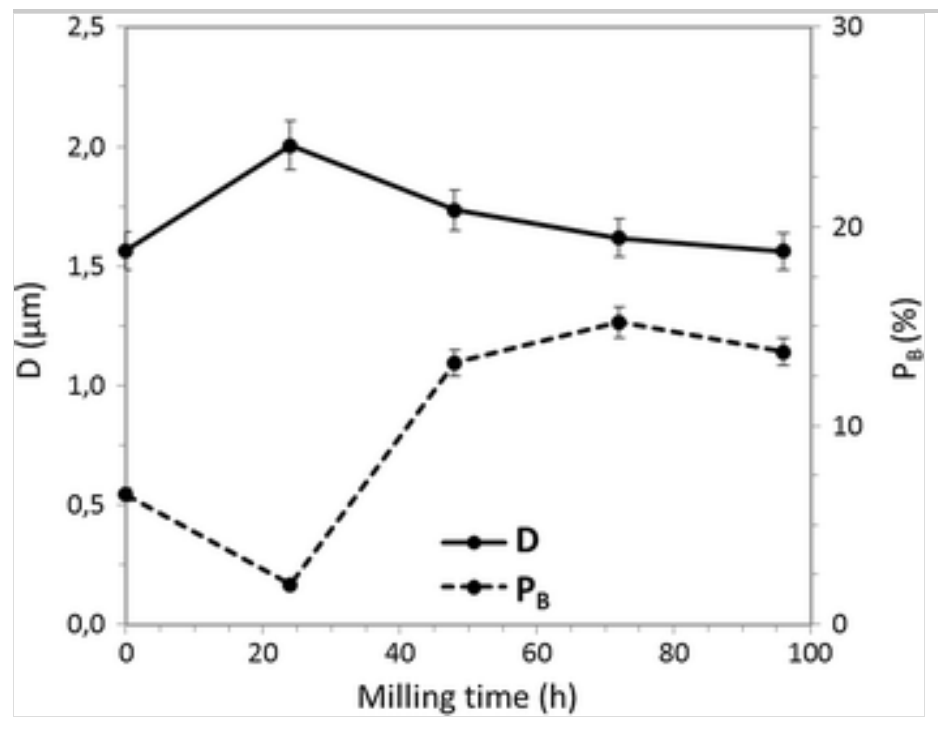

\section{Milling with alumina}

Figure 3 shows the final shape of iron particles after milling with steel balls and different amounts of alumina following the two-step process described above. The evolution of the mean particle size $D$ and $P_{\mathrm{B}}$ with $\mathrm{Al}_{2} \mathrm{O}_{3}$ content is plotted in Fig. 4. The first step was prepared so as to transform the initial rounded iron particles into flakes and it corresponds exactly to the first $24 \mathrm{~h}$ of the process, in which only steel balls were used (Fig. 3 a). This sample was named "M24hstep1". The second step, in which small and hard alumina was added, was 
designed with the aim of breaking the flakes. The SEM image of dry milled particles with an addition of $9 \mathrm{gl}^{-1}$ (Fig. $3 \mathrm{~b}$ ) shows that this goal was achieved, since a great number of small, flat fragments were originated. It must be noted that a great variability between the different trials was observed as well as numerous remains of former large flakes. However, the breaking of flakes was reflected in a significant decrease of $D$ and an increase of $P_{\mathrm{B}}$. With higher alumina additions, as in the case of $27 \mathrm{~g} \mathrm{l}^{-1}$ (Fig. 3c), the remains of large flakes disappeared and milled particles became more homogeneous. It resulted in a large reduction of the mean particle size, but in many cases the particles still maintained a flat form. When the amount of $\mathrm{Al}_{2} \mathrm{O}_{3}$ added was $54 \mathrm{~g} \mathrm{l}^{-1}$, an improvement in milled particles was observed (Fig. $3 \mathrm{~d}$ ). Firstly, the variability between the different trials was reduced and the morphology of milled particles changed from flat to more irregular as a result of bonding between the very small fragments. On the other hand, a slight particle size reduction was observed compared with $27 \mathrm{~g} \mathrm{l}^{-1}: D$ was reduced to less than $0.5 \mu \mathrm{m}$ and $P_{\mathrm{B}}$ was above $93 \%$. Finally, with large $\mathrm{Al}_{2} \mathrm{O}_{3}$ concentrations $\left(108 \mathrm{~g} \mathrm{l}^{-1}\right)$ the tests were difficult to carry out due to a significant increase of pressure and temperature inside vials that resulted in leaks. As the particle size distributions were also worse, these large concentrations were discarded.

\section{Fig. 3}

SEM images of milled particles after the two-step process with the addition of different amounts of alumina. a after first step (M24h-step1), b $9 \mathrm{~g} \mathrm{l}^{-1}$, c $27 \mathrm{~g} \mathrm{l}^{-1}$, d $54 \mathrm{~g} \mathrm{l}^{-1}$ 


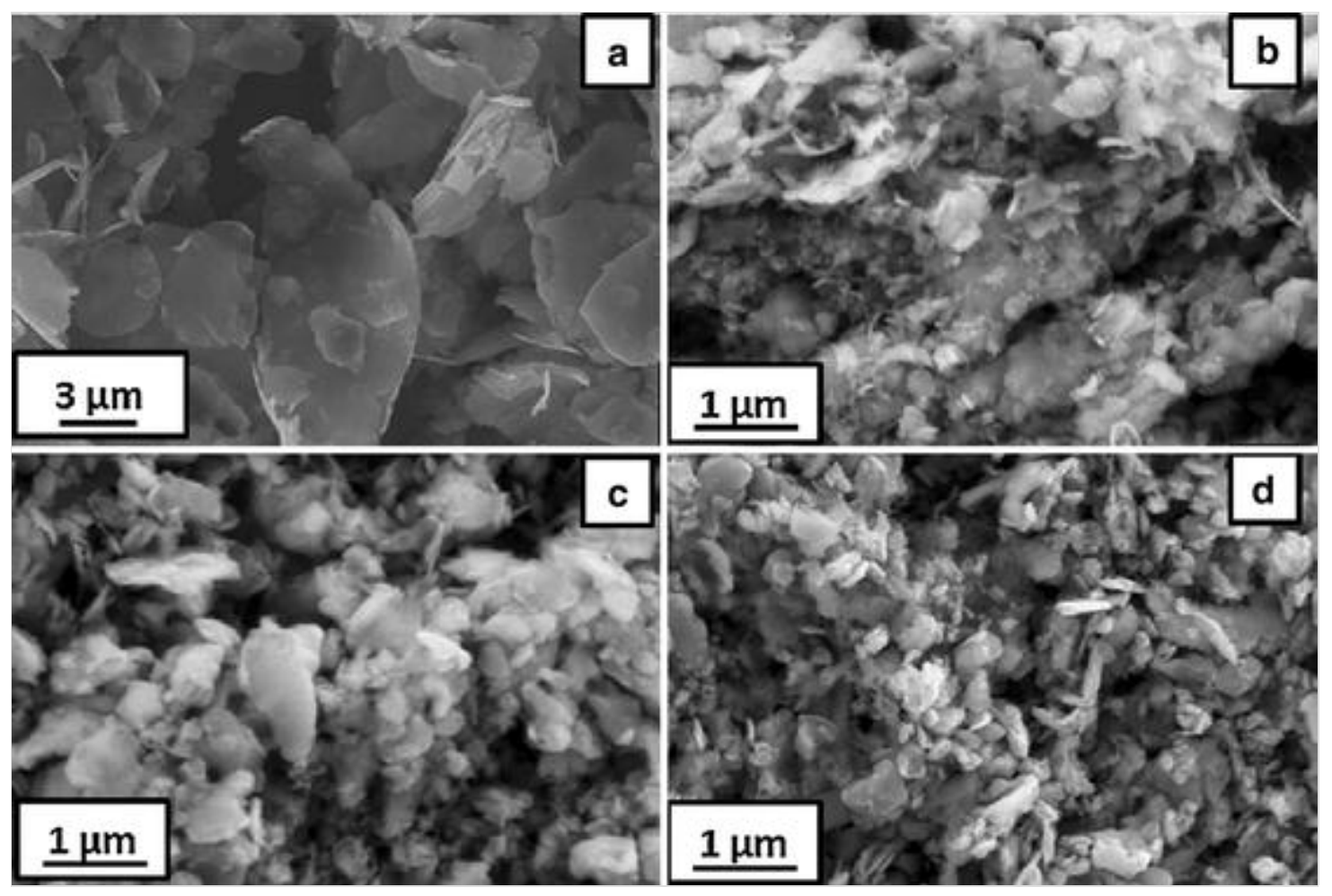

Fig. 4

Evolution of the mean particle diameter $D$ and percentage of particles below $1 \mu \mathrm{m} P_{\mathrm{B}}$ with alumina concentration after additional milling of M24h-step1 for $24 \mathrm{~h}$

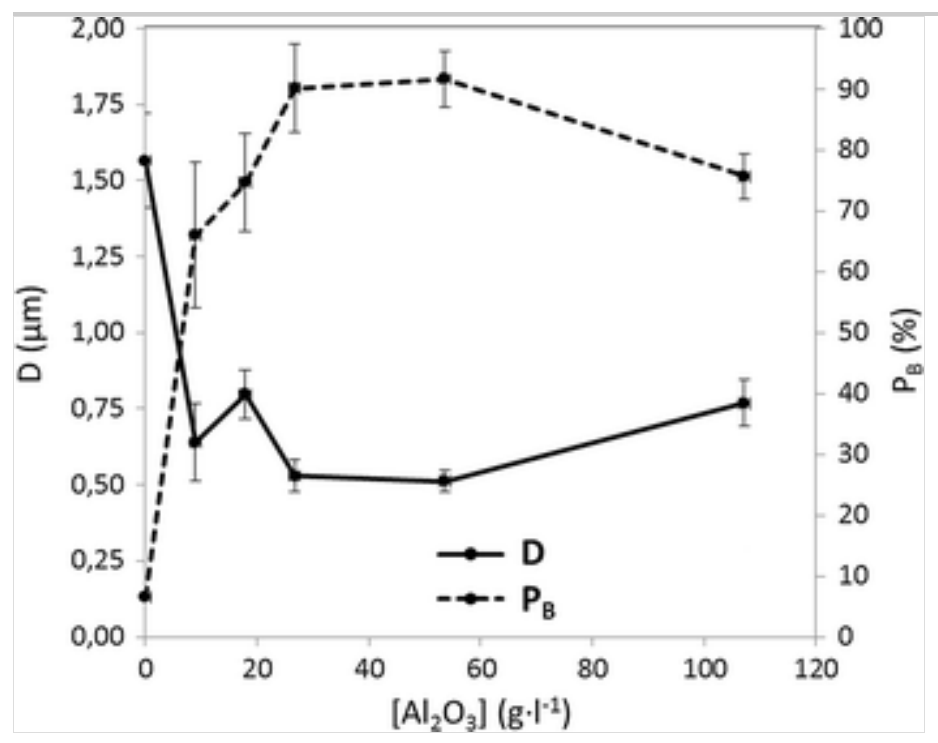

In the light of these results, the milling process with $54 \mathrm{~g} \mathrm{l}^{-1}$ of $\mathrm{Al}_{2} \mathrm{O}_{3}$ was chosen for further characterization and reactivity tests. This sample was named "M48h- $\mathrm{Al}_{2} \mathrm{O}_{3}$ "; TEM images for this sample are shown in Fig. 5. At low magnifications (Fig. $5 \mathrm{a}$ ), the irregular and fragmented shapes of milled particles 
created by the fracture of former flakes can be observed. At higher magnifications, it can be noted that many of the particles have been formed by the joining of smaller fragments (Fig. 5 c). The dark-field image in Fig. $5 \mathrm{c}$ shows that these iron particles have a nanocrystalline structure, with grains of only a few nanometres (Fig. $5 \mathrm{~d}$ ). This type of structure is frequent after ball milling of iron (Rodríguez-Baracaldo et al. 2007; Liu et al. 2001). The analysis of the diffraction rings included in the Selected-Area Diffraction (SAD) of Fig. 5c confirmed that the particles were composed entirely of $\alpha$-Fe grains with a random orientation. It must be noted that there were few points in the SAD that suggest a residual presence of $\mathrm{Al}_{2} \mathrm{O}_{3}$. Unlike other air-stabilized or water aged nZVI particles (Kim et al. 2010), there was an absence of an oxide layer on the outside of the particles (Fig. $5 \mathrm{~b}$ ), which can be explained by the protective coating of MEG and argon atmosphere during milling (Köber et al. 2014). The lack of oxide layer is consistent with the high $\mathrm{Fe}(0)$ content of the $\mathrm{M} 48 \mathrm{~h}-\mathrm{Al}_{2} \mathrm{O}_{3}$ suspension which was $92 \% \pm 1$.

\section{Fig. 5}

TEM images of $\mathrm{M} 48 \mathrm{~h}-\mathrm{Al}_{2} \mathrm{O}_{3}$. a General view. b Details of the nanoparticles' surface. c Bright-field (left) and dark-field (right) images and selected area diffraction (SAD) of milled particles. d Detailed image of a nanostructure within an iron nanoparticle

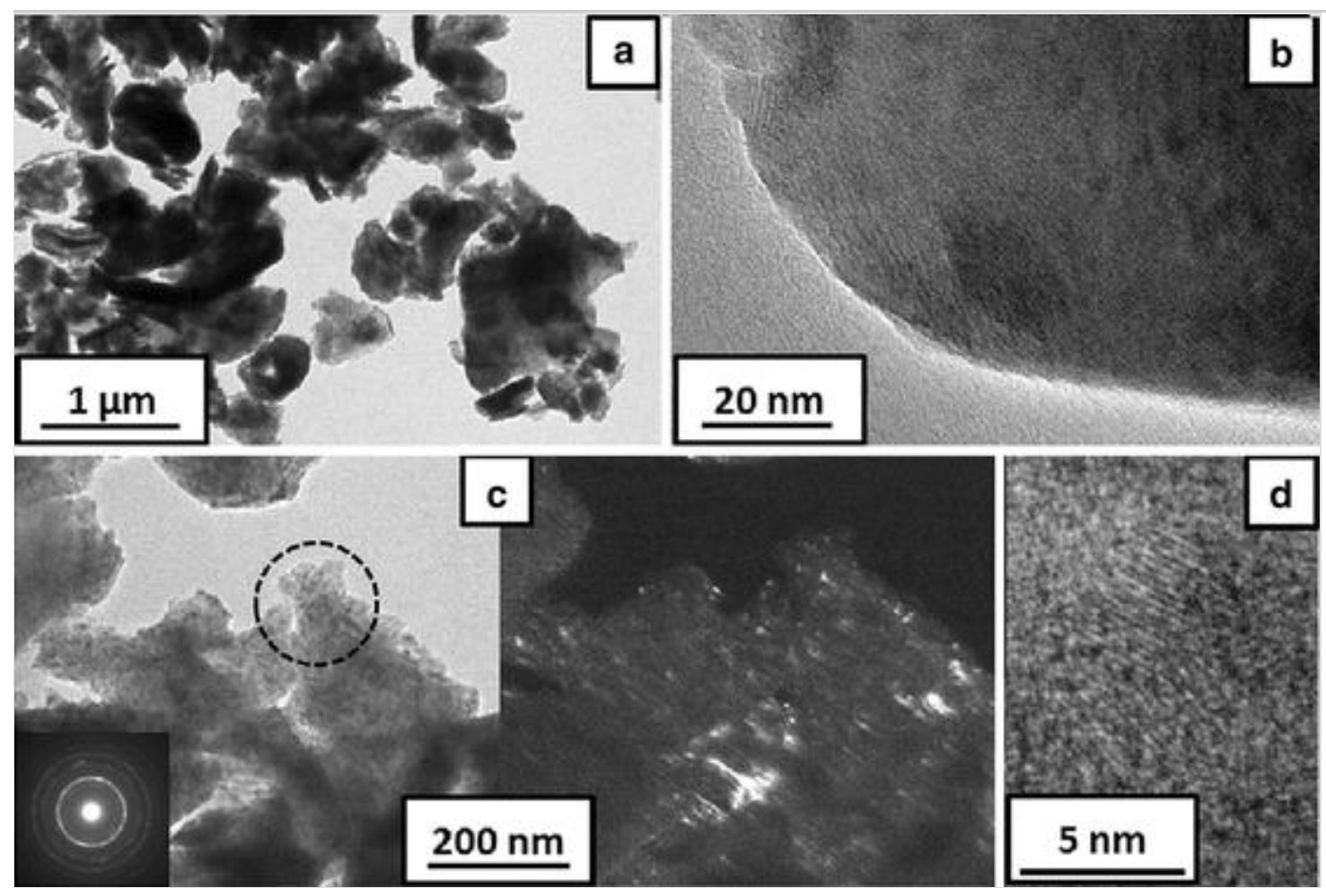


Figure 6 shows the comparison of $D$ in a solution as determined by LDPSA for the initial material; the milled particles after the first and second step (M24h-step1 and $\mathrm{M} 48 \mathrm{~h}-\mathrm{Al}_{2} \mathrm{O}_{3}$, respectively) and the two nZVI commercial products used in the reactivity tests ( $\mathrm{N} 25 \mathrm{P}$ and $\mathrm{A} 01)$. Regarding milled materials, the particle size distribution of M24h-step1 moved to higher equivalent diameters than those of the initial powder due to the change from spherical to flaky morphology. After the second milling step, the fracture process of flakes moved the particle size distribution to lower values, with a mean equivalent diameter below $0.5 \mu \mathrm{m}$. The diameter of the milled particles in the present case is higher than the particle size of typical nZVI particles produced by gas reduction, as is the case of N25P, which are in the range of 50-150 nm (Soukupova et al. 2015; NanoIron 2016). However, when compared with $\mathrm{M} 48 \mathrm{~h}-\mathrm{Al}_{2} \mathrm{O}_{3}$, a significant shift in the average particle size towards larger values was detected for N25P, which means a higher degree of agglomeration. The other milled iron chosen for comparison (A01) has a better particle size distribution than M24-step 1, but is larger than $\mathrm{N} 25 \mathrm{P}$ and $\mathrm{M} 48 \mathrm{~h}-\mathrm{Al}_{2} \mathrm{O}_{3}$.

\section{Fig. 6}

Particle size distribution curves; the as-received iron powder (BASF CIP-SM), iron after the first milling step (M24h-step1), iron after milling with alumina (M48h$\mathrm{Al}_{2} \mathrm{O}_{3}$ ) and commercial reference irons $\mathrm{N} 25 \mathrm{P}$ and $\mathrm{A} 01$

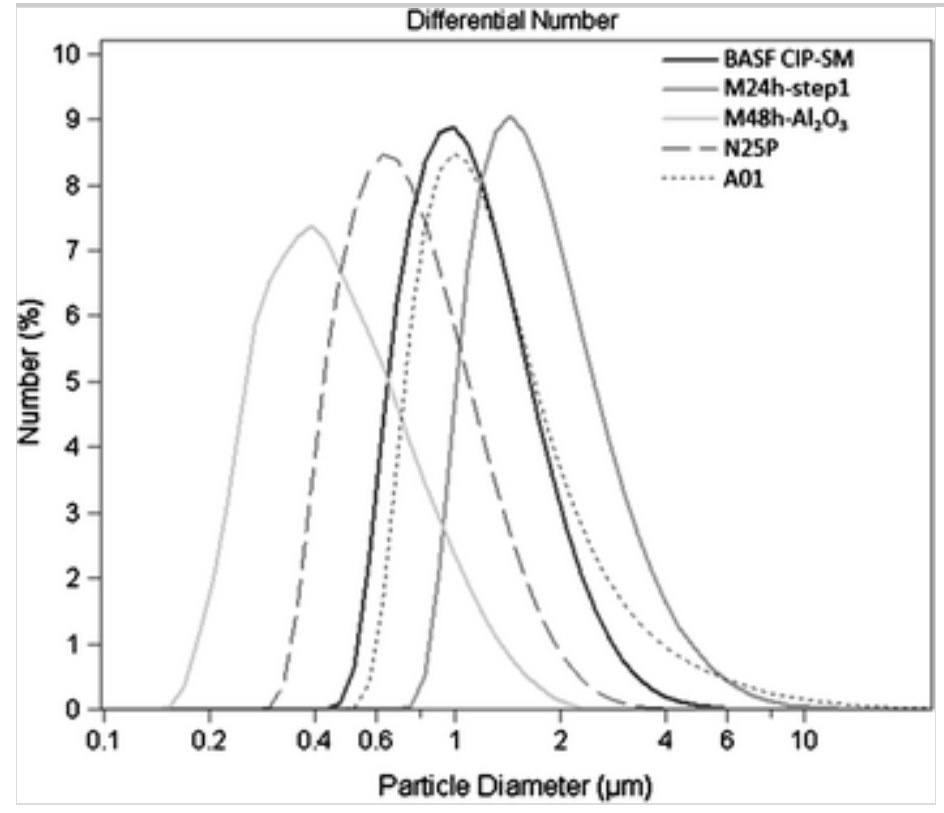

As mentioned above, the $\mathrm{Fe}(0)$ content of the $\mathrm{M} 48 \mathrm{~h}-\mathrm{Al}_{2} \mathrm{O}_{3}$ suspension was 
$92 \% \pm 1$. It was found that the other reference products also had high $\mathrm{Fe}(0)$ content: N25P had an $87 \% \pm 1$ and A01 a $74 \% \pm 1$. On the contrary, the SSA value for milled $\mathrm{M} 48 \mathrm{~h}-\mathrm{Al}_{2} \mathrm{O}_{3}$ was $14.0 \pm 0.1 \mathrm{~m}^{2} \mathrm{~g}^{-1}$, slightly below the value reported for A01 (18 $\mathrm{m}^{2} \mathrm{~g}^{-1}$ ) (Köber et al. 2014) and clearly lower than the one for N25P (25 $\left.\mathrm{m}^{2} \mathrm{~g}^{-1}\right)$ (Soukupova et al. 2015).

\section{Reactivity of the developed iron}

Figure 7 shows the depletion of $\mathrm{Cr}(\mathrm{VI})$ in a solution with the amount of nZVI used in the reactivity tests, whereas Table 1 shows the slope of the depletion curve of $\mathrm{Cr}(\mathrm{VI})$, the $\mathrm{Cr}(\mathrm{VI})$ removal efficiency as weight of $\mathrm{Cr}(\mathrm{VI})$ removed by weight of $\mathrm{Fe}(0)$ and finally, this $\mathrm{Cr}(\mathrm{VI})$ removal efficiency normalized by SSA. As it can be observed in Fig. 7, the blank with alumina powder in MEG had no effect on the $\mathrm{Cr}(\mathrm{VI})$ concentration, which indicates that alumina is not active in the reduction or sorption of $\mathrm{Cr}(\mathrm{VI})$. At the same time, the activity of nZVI suspensions had a good performance in all the cases, considering that the reactivity tests were done without stirring and buffering of $\mathrm{pH}$ (Buerge and Hug $1997)$. The oxidation of $\mathrm{Fe}(0)$ leads to a high $\mathrm{pH}$ in solution $(\approx 9-10)$ and iron passivation, which reduces the electron transfer from iron nanoparticles (O'Carroll et al. 2013; Sohn Song et al. 2005). This behaviour can be observed in Fig. 8, where the evolution of $\mathrm{Cr}(\mathrm{VI})$ content with time is shown for the case of N25P nanoparticles. In all cases, the Cr(VI) depletion took place mainly within the first $2 \mathrm{~h}$, and subsequent analysis for 2 months did not show significant changes in $\mathrm{Cr}(\mathrm{VI})$ concentration. Passivation of nZVI is a frequently reported problem (Kim et al. 2012; Xie and Cwiertny 2012; Liu and Lowry 2006; Li et al. 2008) and in the specific case of $\mathrm{Cr}(\mathrm{VI})$ reduction, it seems to be related to the growth of $\mathrm{Fe}-\mathrm{Cr}$ compounds on the particle surface (Kerkar et al. $1990)$.

\section{Fig. 7}

Depletion curves of $\mathrm{Cr}(\mathrm{VI})$ for iron milled with alumina $\left(\mathrm{M} 48 \mathrm{~h}-\mathrm{Al}_{2} \mathrm{O}_{3}\right)$ and commercial reference irons N25P and A01 


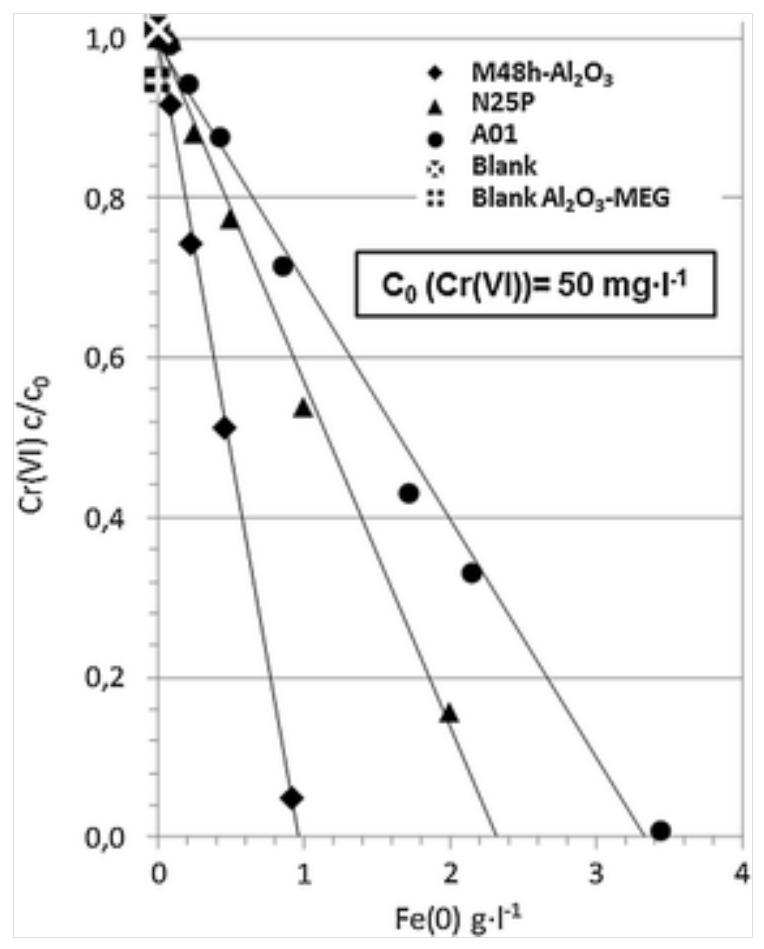

\section{Table 1}

Slopes $(S)$ of the depletion curves of $\mathrm{Cr}(\mathrm{VI}), \mathrm{Cr}(\mathrm{VI})$ removal capacity and normalized Cr(VI) removal capacity by SSA for the three nZVI tested

\begin{tabular}{|l|l|l|l|}
\hline & $\mathrm{S}=\frac{\mathrm{C} / \mathrm{C}_{0}}{[\mathrm{Fe}]}$ & $\begin{array}{l}\text { Cr(VI) removal } \\
\text { capacity }\end{array}$ & $\begin{array}{l}\text { Normalized Cr(VI) removal } \\
\text { capacity by SSA }\end{array}$ \\
\begin{tabular}{|l|l|l|}
$\mathbf{m g ~ C r}(\mathrm{VI}) \mathbf{g}$ \\
$\mathbf{F e}(\mathbf{0})$
\end{tabular} & $\mathbf{m g ~ C r}(\mathrm{VI}) \mathbf{g ~ F e ( 0 )} \mathbf{~ m}^{-\mathbf{- 2}}$ \\
\hline $\mathrm{M} 48 \mathrm{~h}-\mathrm{Al}_{2} \mathrm{O}_{3}$ & -1.035 & 51.9 & 3.7 \\
\hline $\mathrm{N} 25 \mathrm{P}$ & -0.432 & 21.6 & 0.9 \\
\hline $\mathrm{A} 01$ & -0.298 & 15.0 & 0.8 \\
\hline
\end{tabular}

\section{Fig. 8}

Evolution of the $\mathrm{Cr}(\mathrm{VI})$ concentration with time in the reaction batch when N25P nanoparticles were used as reducing reagent 


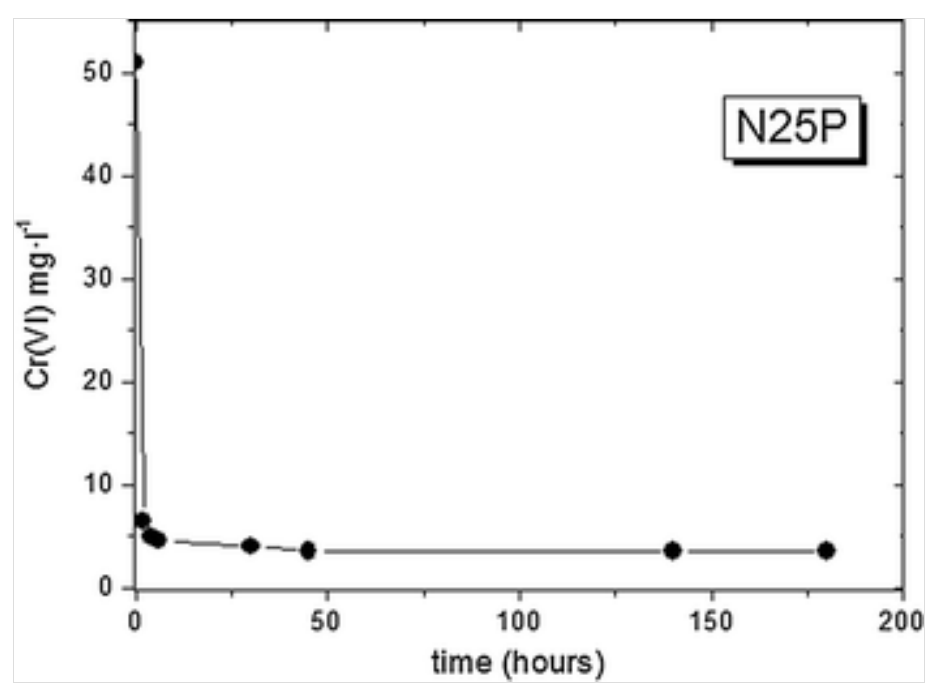

As can be seen in Fig. 7, the $\mathrm{Cr}(\mathrm{VI})$ removal efficiency of $\mathrm{M} 48 \mathrm{~h}-\mathrm{Al}_{2} \mathrm{O}_{3}$ is very high in comparison with the other tested particles, being significantly higher when it is normalized with SSA. M48h- $\mathrm{Al}_{2} \mathrm{O}_{3} \mathrm{Cr}(\mathrm{VI})$ removal efficiency is within the range of the values reported for $\mathrm{nZVI}$ obtained from borohydride method $\left(\mathrm{Fe}^{\mathrm{BH}}\right.$ ) at similar $\mathrm{pH}$ (Li et al. 2008; Xie and Cwiertny 2012; Yu et al. 2014 ). This can be considered as a good result: first, because $\mathrm{Fe}^{\mathrm{BH}}$ is known to have a higher reactivity than other commercial nZVI products (Kim et al. 2012) and second, due to the fact that in the present case the batches were not stirred during reaction.

The high $\mathrm{Cr}(\mathrm{VI})$ removal capacity of $\mathrm{M} 48 \mathrm{~h}-\mathrm{Al}_{2} \mathrm{O}_{3}$ observed can be attributed to different reasons. As described in literature, the main $\mathrm{Cr}(\mathrm{VI})$ removal mechanism is the reduction to $\mathrm{Cr}$ (III) (O'Carroll et al. 2013 ; Li et al. 2008). In this process, the electron transfer from $\mathrm{Fe}(0)$ is a critical point and consequently the presence of a thick oxide layer can cause a reduction of reactivity (O'Carroll et al. 2013; Kim et al. 2010). In the light of the images in Fig. 5 and taking into account the high $\mathrm{Fe}(0)$ content of $\mathrm{M} 48 \mathrm{~h}-\mathrm{Al}_{2} \mathrm{O}_{3}$ particles, no signs indicating the presence of any oxide layer were observed. It is interesting to note that this absence is also applicable to A01 particles (Köber et al. 2014) and N25P (Soukupova et al. 2015; NanoIron 2016). Concerning the milled $48 \mathrm{~h}-\mathrm{Al}_{2} \mathrm{O}_{3}$ particles, the reason for the absence of an oxide layer can be mainly attributed to the use of MEG in the processes of milling and storing particles, which results in a very efficient protection against iron corrosion (Köber et al. 2014). Another important point to consider for a high $\mathrm{Cr}(\mathrm{VI})$ removal capacity is a high SSA, because then a larger number of reactive sites are provided by the particles (O'Carroll et al. 2013). 
However, in this case, the SSA for $\mathrm{M} 48 \mathrm{~h}-\mathrm{Al}_{2} \mathrm{O}_{3}$ is lower than that for the other nZVI, which should result in lower reactivity.

Since the oxide layer and SSA values do not account for the high $\mathrm{Cr}$ (VI) removal capacity of $\mathrm{M} 48 \mathrm{~h}-\mathrm{Al}_{2} \mathrm{O}_{3}$, this high efficiency must be more related to two other factors: the first would be an enhanced density of reactive sites in the surface (Lapuerta et al. 2006), the second would be the internal structure of the nanoparticles (Liu et al. 2005a). In the first point, it has been suggested that the new surfaces created by the fracture of the former particles and the presence of a great amount of irregularities offer a large number of reaction sites, which causes an increase of reactivity (Köber et al. 2014; Li et al. 2009). According to this, the milling process of $\mathrm{M} 48 \mathrm{~h}-\mathrm{Al}_{2} \mathrm{O}_{3}$ has the capacity to break up the iron flakes, which means a large number of fractured surfaces and new and very irregular nanoparticles are formed by the joining of small fragments. Consequently, the reactivity of $\mathrm{M} 48 \mathrm{~h}-\mathrm{Al}_{2} \mathrm{O}_{3}$ particles must then be larger than in the cases where no alumina is used during milling (Köber et al. 2014; Li et al. 2009) or where the particles are not milled, as is the case of N25P (Crane and Scott 2012). Here it should be added that during milling there is a breakdown of the initial oxide layer of former particles which causes a number of the oxides to become finely dispersed throughout the new welded particles, giving rise to new surfaces with less oxygen content (Casas et al. 2015; Li et al. 2009).

The second point is related to the improvement in reactivity associated with an increase in defects in the crystalline structure of iron particles. In this respect, better reactivity has been reported to highly disordered $\mathrm{Fe}^{\mathrm{BH}}$ compared with crystalline nZVI obtained by $\mathrm{H}_{2}$ reduction of iron oxides (Liu et al. 2005a) or by vacuum annealed $\mathrm{Fe}^{\mathrm{BH}}$ (Liu et al. 2005b), although in the latter case the reactivity against some pollutants seems to be unaffected by crystallization during annealing (Dickinson and Scott 2011). In the case of $\mathrm{M} 48 \mathrm{~h}-\mathrm{Al}_{2} \mathrm{O}_{3}$ (Fig. $7 \mathrm{c}, \mathrm{d}$ ) it is composed by nanostructured ferrite obtained by a severe plastic deformation process (Rodríguez-Baracaldo et al. 2007). It is possible to think that this structure is more disordered than that obtained in A01 and N25P. In the first case due to the absence of breakage of the flakes during milling and in the second case by the clear presence of $\alpha$-Fe in X-ray measurements with an average grain size of around 50-100 nm (Soukupova et al. 2015; NanoIron 2016).

\section{Conclusions}


The introduction of fine alumina powder during ball milling of iron in an organic solvent as MEG allows for the breakage of the iron flakes obtained after a more conventional milling process. Low alumina concentrations $\left(9-27 \mathrm{~g} \mathrm{l}^{-1}\right.$ ) render clearly inhomogeneous distributions that are a mixture of remaining former flakes and smaller fragments, whereas high concentrations $\left(108 \mathrm{~g} \mathrm{l}^{-1}\right)$ are difficult to handle due to excessive heating and viscosity of the slurry.

AQ1

When an alumina content of $54 \mathrm{~g} \mathrm{l}^{-1}$ is added, a homogeneous distribution of irregular particles formed from the fragments of the former iron flakes is observed. The vast majority of the particles present an equivalent diameter well below $1 \mu \mathrm{m}$. However, due to the little tendency to aggregation of milled particles, the particle size distribution in solution is clearly finer than that for other commercial nZVI suspensions. In addition, milled particles have high $\mathrm{Fe}_{2}$ (0) content $(92 \pm 1 \%)$ and fairly good specific surface area $\left(14.0 \pm 0.1 \mathrm{~m}^{2} \mathrm{~g}^{-1}\right)$.

The $\mathrm{Cr}(\mathrm{VI})$ removal efficiency is $51.9 \mathrm{mg} \mathrm{Cr}(\mathrm{VI}) \mathrm{g} \mathrm{Fe}(0)^{-1}$, which is higher than the observed in the other commercial nZVI solutions tested in this paper. The reactivity is better when the $\mathrm{Cr}(\mathrm{VI})$ removal capacity is normalized by the specific surface area $\left(3.7 \mathrm{mg} \mathrm{Cr}(\mathrm{VI}) \mathrm{g} \mathrm{Fe}(0)^{-1} \mathrm{~m}^{-2}\right.$ ). This good reactivity comes first from an absence of an oxide layer, but it is thought that the great amount of superficial irregularities that form a great number of reactive sites and the presence of a very fine nanostructure inside the milled particles also play a key role. As a final thought, this procedure is expected to offer a cost-effective way of producing nZVI for large-scale environmental remediation.

AQ2

\section{Acknowledgments}

This work was supported by the EU-Project NANOREM (Taking Nanotechnological Remediation Processes from Lab Scale to End User Applications for the Restoration of a Clean Environment, NMP.2012.1.2-1 FP7-Grant Agreement Nr. 309517).

David Ribas is also grateful to the Spanish MEC under the FPI project for the grant awarded to him (ref. BES-2012-052327) and Miroslav Cernik for the support through the "National Programme for Sustainability I" project LO1201 and the OPR\&DI project of the Centre for Nanomaterials, Advanced 
Technologies and Innovation CZ.1.05/2.1.00/01.0005.

The authors would like to thank PometonEspaña and BASF GmbH for their donation of materials to carry out the project.

\section{References}

Bagchi D, Stohs SJ, Downs BW, Bagchi M, Preuss HG (2002) Cytotoxicity and oxidative mechanisms of different forms of chromium. Toxicology 180(1):5-22

Buerge IJ, Hug SJ (1997) Kinetics and pH dependence of chromium (VI) reduction by iron (II). Environ Sci Technol 31(5):1426-1432

Casas C, Tejedor R, Rodriguez-Baracaldo R, Benito JA, Cabrera JM (2015) The effect of oxide particles on the strength and ductility of bulk iron with a bimodal grain size distribution. Mater Sci Eng A 627:205-216

Crane RA, Scott TB (2012) Nanoscale zero-valent iron: future prospects for an emerging water treatment technology. J Hazard Mater 211:112-125

Dickinson M, Scott TB (2011) The effect of vacuum annealing on the remediation abilities of iron and iron-nickel nanoparticles. J Nanopart Res 13(9):3699-3711

Gheju M (2011) Hexavalent chromium reduction with zero-valent iron (ZVI) in aquatic systems. Water Air Soil Pollut 222(1-4):103-148

Hao L, Lu Y, Asanuma H, Guo J (2012) The influence of the processing parameters on the formation of iron thin films on alumina balls by mechanical coating technique. J Mater Proc Technol 212(5):1169-1176

Kerkar M, Robinson J, Forty AJ (1990) In situ structural studies of the passive film on iron and iron/chromium alloys using X-ray absorption spectroscopy. Faraday Discuss Chem Soc 89(P001):1-20

Kim HS, AhnJY HwangKY, Kim IK, Hwang I (2010) Atmospherically stable nanoscale zero-valent iron particles formed under controlled air contact: characteristics and reactivity. Environ Sci Technol 44(5):1760-1766 
Kim HS, Kim T, Ahn JY, Hwang KY, Park JY, Lim TT, Hwang I (2012) Aging characteristics and reactivity of two types of nanoscale zero-valent iron particles (Fe BH and Fe H2) in nitrate reduction. Chem Eng J 197:16-23

Klimkova S, Cernik M, Lacinova L, Filip J, Jancik D, Zboril R (2011) Zero-valent iron nanoparticles in treatment of acid mine water from in situ uranium leaching. Chemosphere 82(8):1178-1184

Köber R, Hollert H, Hornbruch G, Jekel M, Kamptner A et al (2014) Nanoscale zero-valent iron flakes for groundwater treatment. Environ Earth Sci 72(9):3339-3352

Lapuerta S, Moncoffre N, Millard-Pinard N, Jaffrézic H, Bérerd N et al (2006) Role of proton irradiation and relative air humidity on iron corrosion. J Nucl Mater 352(1):174-181

Li XQ, Cao J, Zhang WX (2008) Stoichiometry of Cr(VI) immobilization using nanoscale zerovalent iron (nZVI): a study with high-resolution X-ray photoelectron spectroscopy (HR-XPS). Ind Eng Chem Res 47(7):2131-2139

Li S, Yan W, Zhang WX (2009) Solvent-free production of nanoscale zero-valent iron (nZVI) with precision milling. Green Chem 11(10):1618-1626

Liu Y, Lowry GV (2006) Effect of particle age (Fe0 content) and solution $\mathrm{pH}$ on NZVI reactivity: $\mathrm{H} 2$ evolution and TCE dechlorination. Environ Sci Technol 40(19):6085-6090

Liu ZG, Hao XJ, Masuyama K, Tsuchiya K, Umemoto M, Hao SM (2001) Nanocrystal formation in a ball milled eutectoid steel. Scr Mater 44(8):1775-1779

Liu Y, Choi H, Dionysiou D, Lowry GV (2005a) Trichloroethene hydrodechlorination in water by highly disordered monometallic nanoiron. Chem Mater 17(21):5315-5322

Liu Y, Majetich SA, Tilton RD, Sholl DS, Lowry GV (2005b) TCE 
dechlorination rates, pathways, and efficiency of nanoscale iron particles with different properties. Environ Sci Technol 39(5):1338-1345

\section{Liu T, Tsang DC, Lo IM (2008) Chromium(VI) reduction kinetics by} zero-valent iron in moderately hard water with humic acid: iron dissolution and humic acid adsorption. Environ Sei Technol 42(6):2092 2098

Melitas N, Chuffe-Moscoso O, Farrell J (2001) Kinetics of soluble chromium removal from contaminated water by zerovalent iron media: corrosion inhibition and passive oxide effects. Environ Sci Technol 35(19):3948-3953

Mueller NC, Braun J, Bruns J, Černík M et al (2012) Application of nanoscale zero valent iron (NZVI) for groundwater remediation in Europe. Environ Sci Pollut Res 19(2):550-558

Mystrioti C, Xenidis A, Papassiopi N (2014) Application of iron nanoparticles synthesized by green tea for the removal of hexavalent chromium in column tests. J Geosci Environ Prot 2(04):28

Nanoiron s.r.o. Nanofer 25P (2016) http://www.nanoiron.cz/en/nanofer-25p. Accessed 04 Mar 2016

O'Carroll D, Sleep B, Krol M, Boparai H, Kocur C (2013) Nanoscale zero valent iron and bimetallic particles for contaminated site remediation. Advin Water Resour 51:104-122

Paesano A Jr et al (2004) Structural and Mössbauer characterization of the ball-milled $\mathrm{Fe}_{\mathrm{x}} /\left(\mathrm{Al}_{2} \mathrm{O}_{3}\right)_{100}$-x/system. J Appl Phys 96(5):2540-2546

Patnaik P (2003) Handbook of inorganic chemicals, vol 28. McGraw-Hill, New York, pp 11-12

Phenrat T, Saleh N, Sirk K, Tilton RD, Lowry GV (2007) Aggregation and sedimentation of aqueous nanoscale zerovalent iron dispersions. Environ Sci Technol 41(1):284-290

Rodríguez-Baracaldo R, Benito JA, Cabrera JM, Prado JM (2007) 
Mechanical response of nanocrystalline steel obtained by mechanical attrition. J Mater Sci 42(5):1757-1764

Smallman RE, Bishop RJ (1999) Modern physical metallurgy and materials engineering. Butterworth-Heinemann, Oxford, pp 323-325

Song H, Carraway ER (2005) Reduction of chlorinated ethanes by nanosized zero-valent iron: kinetics, pathways, and effects of reaction conditions. Environ Sci Technol 39(16):6237-6245

Soukupova J et al (2015) Highly concentrated, reactive and stable dispersion of zero-valent iron nanoparticles: direct surface modification and site application. Chem Eng J 262:813-822

Tang SC, Lo I (2013) Magnetic nanoparticles: essential factors for sustainable environmental applications. Water Res 47(8):2613-2632

Travitzky N, Kumar P, Sandhage KH, Janssen R, Claussen N (2003) Rapid synthesis of $\mathrm{Al}_{z} \mathrm{O}_{3}$ reinforced $\mathrm{Fe}-\mathrm{Cr}-\mathrm{Ni}$ composites. Mater Sci Eng $\mathrm{A}$ $344(1): 245 \quad 252$

Uegami M, Kawano J, Okita T, Fujii Y, Okinaka K, Kayuka K, Yatagi S (2006) Iron particles for purifying contaminated soil or groundwater. US Patent No. 7,022,256

Velimirovic M, Schmid D, Wagner S, Micić V, von der Kammer F, Hofmann T (2015) Agar agar-stabilized milled zerovalent iron particles for in situ groundwater remediation. Sci Total Environ 563:713-723

Wang CB, Zhang WX (1997) Synthesizing nanoscale iron particles for rapid and complete dechlorination of TCE and PCBs. Environ Sci Technol 31(7):2154-2156

Xie Y, Cwiertny DM (2012) Influence of anionic cosolutes and $\mathrm{pH}$ on nanoscale zerovalent iron longevity: time scales and mechanisms of reactivity loss toward 1,1,1,2-tetrachloroethane and Cr(VI). Environ Sci Technol 46(15):8365-8373 
Yan W, Lien HL, Koel BE, Zhang WX (2013) Iron nanoparticles for environmental clean-up: recent developments and future outlook. Environ Sci 15(1):63-77

Yu RF, Chi F-H, Cheng W-P, Chang J-C (2014) Application of pH, ORP, and DO monitoring to evaluate chromium(VI) removal from wastewater by the nanoscale zero-valent iron (nZVI) process. Chem Eng J 255:568-576

Zhang WX (2006) Dispersed zero-valent iron colloids. US Patent No. $7,128,841 \mathrm{~B} 2$ 